\title{
SARS-COV-2 (COVID-19) PONE EN EVIDENCIA LA SITUACIÓN DEL PERSONAL DE LA SALUD EN COLOMBIA
}

Ana Cecilia Becerra Pabón ${ }^{1}$, Sofia Loreney Lagos Mendoza², Yeison Fernando Martínez Carreño², María Claudia Barrera Céspedes ${ }^{4}$

\section{Resumen}

Frente al impacto que ha tenido el Coronavirus SARS-CoV-2 (COVID 19) en el personal de salud en Colombia, se resaltan algunos aspectos que la Pandemia ha puesto en evidencia ante el público en general, frente a la realidad que vive este gremio en Colombia.

Palabras clave: infecciones por Coronavirus, personal de salud

(C) 2021 Fundación Universitaria Juan N. Corpas. FUJNC.

Artículo Open Access bajo la Licencia Creative Commons Atribución-NoComercial-Compartirlgual 4.0 Internacional.

DOI: 10.26752/revistaparadigmassh.v2i2.532

${ }^{1}$ Enfermera, Especialista en Enfermería Materno-Perinatal y Doctora en Ciencias de la Educación. Fundación Universitaria Juan N. Corpas. Bogotá, D.C., Colombia. ORCID 0000-0003-3334-1795. Autor de Correspondencia: Ana Cecilia Becerra Pabón: ana.becerra@juanncorpas.edu.co

${ }^{2}$ Médica, Especialista en Pediatría. Formadora en Procesamiento y Control de Calidad de la Leche Humana, Hospital Federico Lleras Acosta, Ibagué, Colombia. ORCID 0000-0002-4229-0128

${ }^{3}$ Médico, Especialista en Gerencia de Marketing Farmacéutico. Fundación Universitaria de Ciencias de la salud, Bogotá, D.C., Colombia. ORCID 0000-0003-2927-6118

${ }^{4}$ Médico, Especialista en Terapéuticas Alternativas y Farmacología Vegetal y Microbióloga Industrial. Fundación Universitaria Juan N. Corpas, Bogotá, D.C., Colombia. ORCID 0000-0002-8366-3314 


\section{Sr. Editor}

A ocho meses de iniciada la pandemia COVID-19 y hasta agosto del 2020, la región de las Américas, reportaba 569.304 casos en personal de salud, de los cuales 7.692 han ocurrido en ciudades colombianas, principalmente Bogotá, Valle de Cauca, Antioquia, Barranquilla, Cartagena, Nariño, Cundinamarca y Chocó. El 67.2\% de estos casos corresponden a infecciones asociadas a la atención en salud, afectando principalmente auxiliares de enfermería, médicos, enfermeros y administrativos/limpieza. (Informes de situación de la COVID-19 | OPS/OMS | Organización Panamericana de la Salud, s. f.), (Alerta Epidemiológica, s. f.), (Noticias coronavirus-personal-salud, s. f.), (Reporte de Situacion COVID-19 Colombia No. 13402 de septiembrede 2020 - OPS/OMS | Organización Panamericana de la Salud, s. f.)

Pero más allá de las cifras, la pandemia de COVID 19 ha enfrentado al personal de salud a situaciones complejas como la renuncia masiva de médicos, falta de elementos de protección personal, amenazas en sus viviendas, detrimento de las condiciones laborales, etc., ¿tomaremos consciencia por fin de esta realidad?

Según la Contraloría General de la Nación, $45 \%$ de los profesionales de la salud manifiestan que les han modificado sus condiciones laborales, cambiado su contrato, vinculado como prestación de servicios, sin prestaciones, estabilidad, seguridad, les han reducido horas de servicio, modificado salarios y formas de pago, evidenciando la preocupante informalidad del sector salud. (Contraloría General de la República, s. f.)
Esta deslegitimación de los derechos de los profesionales de la salud es un detonante de la ausencia de calidad en la atención de los sujetos de cuidado, que desmotiva y perturba la calidad de vida y el desarrollo humano del personal de la salud.(Menos aplausos y más condiciones laborales | EL ESPECTADOR, s. f.)

La Pandemia ha visibilizado y multiplicado esta realidad ante la cual, el gobierno de turno, ha respondido con medidas de poco impacto, trasladando su responsabilidad, como si asegurar el bienestar de las vidas del personal que labora en primera línea, enfrentando la pandemia, fuera un juego de pelota.

En este contexto, al riesgo laboral y el de una mayor exposición al contagio por el SARS CoV-2, se suma el impacto negativo en la salud mental de los profesionales de salud, el cual, se ha encontrado que, ante emergencias que son ocasionadas por virus, se traduce en una mayor prevalencia de ansiedad, depresión, estrés agudo, burnout y estrés postraumático.(Ricci-Cabello et al., 2020)

Sin duda la pandemia ha revelado la realidad del gremio de la salud, enmarcada en la historia de la educación en salud, que, enfocada específicamente en la enfermedad, deja poco espacio al pensamiento crítico generando profesionales que ejercen su labor desde la obediencia con poco sentido gremial, dando lugar a que políticos y administradores tomen las riendas de nuestro sistema de salud provocando las consecuencias que vivimos en clínicas y hospitales de todo Colombia. 
Es desalentador que no se vislumbren soluciones definitivas que resuelvan las dificultades que enfrentan los profesionales de la salud, de ahí la necesidad que la actual pandemia sea un despertador de conciencias, especialmente en el personal de salud, para que como gremio se promuevan y generen políticas que finalmente los beneficien integralmente permitiendo ejercer las profesiones de la salud desde el bienestar y no desde la competencia.
Declaración sobre conflicto de intereses: como autores manifestamos que somos independientes con respecto a las instituciones que apoyaron este documento y que durante la redacción del manuscrito no hemos incidido intereses o valores diferentes a los que usualmente tiene la investigación. No tenemos ningún conflicto de interés.

\section{Referencias Bibliográficas}

1. Informes de situación de la COVID-19 | OPS/OMS | Organización Panamericana de la Salud. (s. f.). Recuperado 15 de marzo de 2021, de https://www.paho.org/es/informes-situacioncovid-19

2. Alerta Epidemiológica: COVID-19 en personal de salud - 31 de agosto de 2020 - OPS/ OMS | Organización Panamericana de la Salud. (s. f.). Recuperado 15 de marzo de 2021, de https://www.paho.org/es/documentos/alerta-epidemiologica-covid-19-personal-salud-31agosto-2020

3. Noticias coronavirus-personal-salud. (s. f.). Recuperado 15 de marzo de 2021, de https://www. ins.gov.co/Noticias/Paginas/coronavirus-personal-salud.aspx

4. Reporte de Situacion COVID-19 Colombia No. 134- 02 de septiembrede 2020-OPS/ OMS | Organización Panamericana de la Salud. (s. f.). Recuperado 15 de marzo de 2021, de https://www.paho.org/es/documentos/reporte-situacion-covid-19-colombia-no-134-02septiembrede-2020

5. Página de inicio-Contraloría General de la República. (s. f.). Recuperado 15 de marzo de 2021, de https://www.contraloria.gov.co/

6. Menos aplausos y más condiciones laborales | EL ESPECTADOR. (s. f.). Recuperado 15 de marzo de 2021, de https://www.elespectador.com/opinion/menos-aplausos-y-mas-condicioneslaborales-columna-911871/

7. Ricci-Cabello, I., Meneses-Echavez, J. F., Serrano-Ripoll, M. J., Fraile-Navarro, D., de Roque, M. A. F., Moreno, G. P., Castro, A., Ruiz-Pérez, I., Campos, R. Z., \& Gonçalves-Bradley, D. (2020). Impact of viral epidemic outbreaks on mental health of healthcare workers: A rapid systematic review [Preprint].Psychiatryand Clinical Psychology.https://doi.org/10.1101/2020.04.02.20048892 